\title{
BMJ Open Geospatial analysis of pediatric surgical need and geographical access to care in Somaliland: a cross-sectional study
}

\author{
Cesia F Cotache-Condor (10 , ${ }^{1}$ Katelyn Moody, ${ }^{1}$ Tessa Concepcion, ${ }^{2}$ \\ Mubarak Mohamed, ${ }^{3}$ Shukri Dahir, ${ }^{3}$ Edna Adan Ismail, ${ }^{4}$ Jonathan Cook, ${ }^{5}$ \\ John Will, ${ }^{5}$ Henry E Rice, ${ }^{2,6}$ Emily R Smith (1) ${ }^{1,2}$
}

To cite: Cotache-Condor $\mathrm{CF}$, Moody K, Concepcion T, et al. Geospatial analysis of pediatric surgical need and geographical access to care in Somaliland: a cross-sectional study. BMJ Open 2021;11:e042969. doi:10.1136/ bmjopen-2020-042969

- Prepublication history and additional supplemental material for this paper are available online. To view these files, please visit the journal online. To view these files, please visit the journal online (http://dx.doi org/10.1136/bmjopen-2020042969).

CFC-C and KM are joint first authors.

Received 20 July 2020

Accepted 05 July 2021

Check for updates

(C) Author(s) (or their employer(s)) 2021. Re-use permitted under CC BY-NC. No commercial re-use. See rights and permissions. Published by BMJ.

For numbered affiliations see end of article.

Correspondence to

Dr Emily R Smith;

emily_r_smith@baylor.edu

\section{ABSTRACT}

Background The global burden of disease in children is large and disproportionally affects low-income and middle-income countries (LMICs). Geospatial analysis offers powerful tools to quantify and visualise disparities in surgical care in LMICs. Our study aims to analyse the geographical distribution of paediatric surgical conditions and to evaluate the geographical access to surgical care in Somaliland.

Methods Using the Surgeons OverSeas Assessment of Surgical Need survey and a combined survey from the WHO's (WHO) Surgical Assessment Tool—Hospital Walkthrough and the Global Initiative for Children's Surgery Global Assessment in Paediatric Surgery, we collected data on surgical burden and access from 1503 children and 15 hospitals across Somaliland. We used several geospatial tools, including hotspot analysis, service area analysis, Voronoi diagrams, and Inverse Distance Weighted interpolation to estimate the geographical distribution of paediatric surgical conditions and access to care across Somaliland.

Results Our analysis suggests less than $10 \%$ of children have timely access to care across Somaliland. Patients could travel up to 12 hours by public transportation and more than 2 days by foot to reach surgical care. There are wide geographical disparities in the prevalence of paediatric surgical conditions and access to surgical care across regions. Disparities are greater among children travelling by foot and living in rural areas, where the delay to receive surgery often exceeds 3 years. Overall, Sahil and Sool were the regions that combined the highest need and the poorest surgical care coverage.

Conclusion Our study demonstrated wide disparities in the distribution of surgical disease and access to surgical care for children across Somaliland. Geospatial analysis offers powerful tools to identify critical areas and strategically allocate resources and interventions to efficiently scale-up surgical care for children in Somaliland.

\section{INTRODUCTION}

The Lancet Commission on Global Surgery's (LCoGS) call for universal access to surgical care has brought global attention to surgical care, especially in low/middle-income countries (LMICs). ${ }^{1} 2$ The LCoGS developed
Strengths and limitations of this study

- In combination with a nationwide household survey, geospatial analysis offers powerful tools to estimate the geographical distribution of paediatric surgical conditions and to identify geographical barriers and delays or lack in surgical care in Somaliland.

- Geospatial analysis can help guide strategic scaleup of paediatric surgical interventions and allocation of resources by identifying critical areas in need.

- Unlike previous studies, geographical access to paediatric surgical care was stratified by public transportation and on foot transportation.

- Although there is no consensus about how to categorise a bellwether hospital for children, we attempted to analyse access to care by differentiating between surgically capable hospitals and bellwether hospitals.

- Estimates of travel time may be inaccurate due to incomplete knowledge of the extent of damage to the road network caused by previous civil conflict in Somaliland, topographic barriers, and waiting times. Therefore, real travel times might be longer than estimated travel times in this study.

indicators to ensure a country has the capacity for safe, affordable, and timely surgical care. The first indicator, access to timely essential surgery, is the proportion of the population that can access within 2 hours to a facility that has capacity for caesarean section, laparotomy, and treatment of open fracture (the bellwether procedures). ${ }^{3}$ Although several studies have addressed how to assess timely access to care for adults, ${ }^{4-8}$ there is a lack of literature surrounding analysis of access to surgical care for children in LMICs.

Geospatial analysis has become an essential tool to understand the bigger picture of public health. ${ }^{9}$ Specific techniques such as hotspot analysis and interpolation methods have provided in-depth insight regarding the spatial distribution of disease in terms of incidence or prevalence in epidemiological 
studies. ${ }^{10}$ In addition to that, tools for service area analysis can be used to address the growing disparities in health services and help local and national administrators to re-evaluate their healthcare systems to accommodate the current population needs. ${ }^{11}$ Geospatial analysis offers powerful tools to estimate the geographical distribution of surgical conditions and access to care. In combination with nationwide household surveys, geospatial tools have been used to identify geographical barriers and delays or lack in receiving surgical care in several LMICs, including Zambia, ${ }^{7}$ Ghana, ${ }^{12}$ Nepal, ${ }^{13}$ Uganda, ${ }^{14-16}$ Zimbabwe $^{17}$ and Brazil. ${ }^{18}$ In several of these studies, barriers related to distance, transportation, financial hardship, topography and road conditions are predictive of access to surgical services. Geospatial analysis can help guide strategic scale-up of surgical interventions and allocation of resources by identifying critical areas in need. ${ }^{15}$

In Somaliland, there are tremendous challenges with the provision of surgical care for children. In a previous study, our team found a $12 \%$ prevalence of paediatric surgical conditions across the country, with up to $75 \%$ of children having unmet needs for surgical care. ${ }^{19}$ The purpose of this study was to use geospatial analysis techniques to analyse the distribution of paediatric surgical conditions and to evaluate the geographical access to surgical care in Somaliland. We also provide recommendations for scaling-up interventions aimed to alleviate the high surgical burden for children in Somaliland.

\section{METHODS}

\section{Country overview}

Somaliland is a low-income country in sub-Saharan Africa with a gross domestic product per capita of US\$566 in 2018, classifying it as one of the poorest countries in the world. ${ }^{20}$ During the Somali civil war, many healthcarerelated institutions were weakened or destroyed, with loss of a large portion of the trained healthcare staff. ${ }^{21}$ As a young post-conflict country and not formally recognised by the international community, Somaliland faces many challenges rebuilding its health system. ${ }^{21}{ }^{22}$ Although the portion of the national budget allocated for the health sector has increased from $3 \%$ in 2011 to $5 \%$ in 2020, with health expenditures increasing from US $\$ 5$ million to US $\$ 11$ million, respectively, these improvements have not kept pace with population growth and the double burden of disease and poverty. ${ }^{23}$ Somaliland has a surface area of $190797 \mathrm{~km}^{2}$ and a population of 4 million people distributed in six regions: Awdal, Maroodi Jeex, Sahil, Sanaag, Sool and Togdheer. ${ }^{20}$ Like many other LMICs, children younger than 15 years make up $50 \%$ of the population in Somaliland. ${ }^{24}$

\section{Study design, participants and data collection}

This cross-sectional study is built on data collected by our team in previous studies and complies with the Strengthening the Reporting of Observational Studies in Epidemiology Statement (online supplemental material
1). ${ }^{192526}$ From August to December 2017, we collected data on the burden of paediatric surgical conditions across Somaliland using a community-based sampling survey. We also performed capacity assessment of all hospitals capable of performing surgery, with methods described in depth in the parent studies. ${ }^{19} 25$

For the burden of disease assessment, we used the Surgeons OverSeas Assessment of Surgical Need, which is a validated, cluster-based, and cross-sectional survey designed for a community-level health assessment. To obtain a representative sample of all six regions using a proportional-to-size methodology, Somaliland was divided into 25 survey sites randomly selected in a 2-stage process. First, 20 households were selected as a target number for each survey site, resulting in a total of 838 households that were successfully surveyed. Second, up to 2 children were enrolled within each household, making up to a total of 1503 children. Online supplemental material 2 depicts the distribution of sample sites by region. Population estimates used in dot density maps were based on the Population Estimation Survey 2014 for the 18 prewar regions of Somalia. ${ }^{27}$ The sample size was calculated using a paediatric surgical disease prevalence of $19 \%$, as reported in other LMICs. ${ }^{28-30}$ A 'child' was defined as a person up to age 15 years. A 'surgical condition' was defined according to the LCoGS as 'any disease, illness, or injury in which surgical care can potentially improve the outcome'. ${ }^{3}$ The prevalence of surgical conditions was determined as the rate of children who reported a surgical condition at some point in their life.

For hospital assessment, we used the WHO's Surgical Assessment Tool-Hospital Walkthrough and the Global Initiative for Children's Surgery's Global Assessment in Paediatric Surgery. ${ }^{31}{ }^{32}$ Both surveys were combined to create a hospital assessment tool to assess surgical infrastructure and capacity. Hospitals were included if they had at least one operating room, with 15 hospitals included in this study. Online supplemental material 3 depicts the distribution of hospitals by region. Surveys were completed by either the lead surgeon or administrator at each hospital. Data collected included hospital location, availability of paediatric beds, operative procedures and obstetrical deliveries during a 6-month period. During data collection, global positioning system (GPS) coordinates were collected at each community participant's house and at each hospital using a smartphone GPS application.

\section{Data analysis}

According to the LCoGS, the bellwether procedures (laparotomy, open fracture fixation and caesarean section) are indicators of a functional health system that can treat a broad range of surgical conditions. ${ }^{3}$ Hospitals in this study were defined as 'surgically capable' if they had at least one operating room, and were defined as a 'bellwether hospital' if in addition of being a surgically capable hospital, they reported performing at least one laparotomy, at least one open fracture fixation, and at 
Table 1 Summary of geospatial analysis tools and related objectives and data used as part of the study's methodology

\begin{tabular}{ll}
\hline Geospatial tools & Objective and details \\
\hline $\begin{array}{l}\text { 1.Inverse distance } \\
\text { weighted (IDW) }\end{array}$ & $\begin{array}{l}\text { Estimate the geographical distribution of paediatric surgical } \\
\text { conditions stratified by age and time of delay to receive surgical } \\
\text { interpolation }\end{array}$ \\
care.
\end{tabular}

2.Hotspot analysis Identify statistically significant (90\%, $95 \%$ and $99 \%)$ clusters of untreated surgical conditions (also called 'unmet surgical care').

Data used

SOSAS survey: prevalence of paediatric surgical conditions $(\mathrm{n}=221)$ among 196 children. Areas of most vulnerability and highest priority for future interventions $(n=168)$ among 196 children. regarding age and time of delay were depicted as red bullets.

3.Service area-Network Evaluate geographical accessibility to surgical care based on the Analyst time needed to reach surgically capable and bellwether hospitals. Optimal accessibility was defined as a catchment area within a 2hour distance, as suggested by the LCoGS. ${ }^{3}$ Distances calculated for travelling by public transportation and by foot were based on the national road network instead of a straight-line distance (Euclidean distance). Distances were broken down into six categories, including $\leq 2$ hours (optimal), 2-6 hours, 6-12 hours, 12-14 hours, 1-2 days, and $\geq 2$ days. We assumed a constant speed limit of $30 \mathrm{~km} / \mathrm{hour}$ for public transportation and $5 \mathrm{~km} /$ hour for travel on foot. The child population inside a 2 hour distance (called 'catchment population') was estimated in a two-step process. First, the child population density was calculated at a regional level. Second, the regional child population density was multiplied by the area $\left(\mathrm{km}^{2}\right)$ corresponding to $\leq 2$ hours in the service area map. Estimates at the national level were calculated by using the national population density.

4.Voronoi diagrams Evaluate the crude area of coverage $\left(\mathrm{km}^{2}\right)$ for surgically capable and bellwether hospitals. We assumed that patients travel to the closest hospital. If no hospital was available within the region, then we assumed that patients would travel to the closest hospital from a neighbouring region. The hospital area of coverage $\left(\mathrm{km}^{2}\right)$ at the regional level was calculated as the average of the polygons within each region. A polygon was counted for a specific region only if its related hospital point was inside that region (online supplemental material 4).

Hospital assessment for 15 healthcare facilities. Road network ${ }^{41}$
Hospital assessment for 15 healthcare facilities.

All analyses were performed by using ArcMap packages.

LCoGS, Lancet Commission on Global Surgery; SOSAS, Surgeons OverSeas Assessment of Surgical Need.

least one caesarean section over a 6 -month period. Hospitals that performed only one or two of these bellwether procedures were not considered a bellwether hospital.

From a total of 1503 children surveyed across Somaliland, 196 children reported one or more surgical conditions, adding up to a total of 221 surgical conditions. ${ }^{19}$ These 221 surgical conditions were categorised by children's age $(<5$ years old, $6-10$ years old and $>10$ years old), untreated conditions $(\mathrm{n}=168)$, and delay to receive surgical care from onset of symptoms $(<1$ month, 1-12 months, 1-3 years, $>3$ years). Descriptive statistics were generated using SAS V.9.4 (SAS Institute).

\section{Geospatial analysis}

We evaluated the geographical distribution of paediatric surgical conditions and timely access to surgical care across Somaliland. All data were displayed using geospatial choropleth maps and analysed using four geospatial tools described in table 1 . Choropleth maps were weighted using the survey sites' population density estimates. All geospatial analyses were performed in ArcMap V.10.3 (ESRI, Redlands, California).

\section{Patient and public involvement}

Patients or the public were not involved in the design, or conduct, or reporting, or dissemination plans of our research.

\section{RESULTS}

Our analysis revealed wide disparities in the prevalence of paediatric surgical conditions, the proportion of unmet surgical need, and geographical access to timely surgical care across Somaliland. Overall, Sahil and Sool were the regions with the highest need and the poorest surgical care coverage within a 2-hour distance from a bellwether capable hospital.

\section{Children demographics and hospital characteristics}

Most children (83\%) having surgical conditions reported travelling by foot to access healthcare services (table 2). 
Table 2 Characteristics of 15 hospitals and 196 children that reported one or more surgical conditions from a total of 1503 children surveyed across Somaliland

\begin{tabular}{|c|c|c|c|c|c|c|c|}
\hline & $\begin{array}{l}\text { Total } \\
\%(n)\end{array}$ & $\begin{array}{l}\text { Awdal } \\
\% \text { (n) }\end{array}$ & $\begin{array}{l}\text { Maroodi J. } \\
\% \text { (n) }\end{array}$ & $\begin{array}{l}\text { Sahil } \\
\% \text { (n) }\end{array}$ & $\begin{array}{l}\text { Sanaag } \\
\%(n)\end{array}$ & $\begin{array}{l}\text { Sool } \\
\% \text { (n) }\end{array}$ & $\begin{array}{l}\text { Togdheer } \\
\% \text { (n) }\end{array}$ \\
\hline \multicolumn{8}{|l|}{ Children } \\
\hline \multicolumn{8}{|l|}{ Primary transport } \\
\hline On foot & $83.5(154)$ & $100.0(16)$ & 82.7 (99) & $100.0(13)$ & $100.0(8)$ & $70.4(8)$ & $67.4(10)$ \\
\hline Public transportation & $12.6(26)$ & $0.0(0)$ & $12.6(18)$ & $0.0(0)$ & $0.0(0)$ & $19.7(2)$ & $29.7(6)$ \\
\hline Private car & $3.9(7)$ & $0.0(0)$ & $4.7(5)$ & $0.0(0)$ & $0.0(0)$ & $9.9(1)$ & $2.9(1)$ \\
\hline Unknown & (9) & & & & & & \\
\hline \multicolumn{8}{|l|}{ Hospitals } \\
\hline Surgical capable hospitals & $100.0(15)$ & $20.0(3)$ & $40.0(6)$ & $13.3(2)$ & $6.7(1)$ & $6.7(1)$ & $13.3(2)$ \\
\hline Operating rooms & $100.0(42)$ & $19.0(8)$ & $54.8(23)$ & $9.5(4)$ & $2.4(1)$ & $7.1(3)$ & $7.1(3)$ \\
\hline Paediatric beds & $100.0(216)$ & $28.7(62)$ & $38.9(84)$ & $12.0(26)$ & $9.3(20)$ & $0.0(0)$ & $11.1(24)$ \\
\hline Bellwether hospitals & $100.0(5)$ & $40.0(2)$ & $40.0(2)$ & $0.0(0)$ & $20.0(1)$ & $0.0(0)$ & $0.0(0)$ \\
\hline Operating rooms & $100.0(16)$ & $31.3(5)$ & $62.5(10)$ & $0.0(0)$ & $6.25(1)$ & $0.0(0)$ & $0.0(0)$ \\
\hline Paediatric beds & $100.0(109)$ & $45.9(50)$ & $35.8(39)$ & $0.0(0)$ & $18.3(20)$ & $0.0(0)$ & $0.0(0)$ \\
\hline
\end{tabular}

All children (100\%) in Awdal, Sahil and Sanaag reported travelling by foot. From a total of 15 hospitals included in this study, all were classified as surgically capable hospitals, and 5 of them were classified as bellwether hospitals. Maroodi Jeex included the highest number of surgically capable hospitals $(40 \%, \mathrm{n}=6)$, while Sanaag and Sool included the smallest number $(7 \%, \mathrm{n}=1)$. No bellwether hospitals were found in Sahil, Sool and Togdheer.

\section{Geospatial distribution of surgical conditions, by age and time} of delay

The prevalence of surgical conditions was highest in Awdal $(30 \%-33 \%)$, with slightly lower levels in northern Maroodi Jeex, south-western Sahil, and southern Sool $(20 \%-30 \%)$. Hot spots of untreated surgical conditions were found in southern Awdal, northern Sahil and northeastern Maroodi Jeex (figure 1).

Stratification of surgical conditions by age revealed that Sahil had the highest prevalence of surgical conditions for children $<5$ years old and children older than 10 years old $(12 \%-16 \%)$, but south-eastern Awdal had the highest prevalence for children $6-10$ years $(16 \%-20 \%)$ (figure 2A). Analysis of untreated surgical conditions stratified by delay to receive surgery revealed less than $4 \%$ of children had a delay of less than a month across all regions. However, south-eastern Awdal (20\%-24\%) and south-western Sanaag (12\%-16\%) had the highest rate of children with a delay of more than 3 years (figure 2B).

\section{Geographical access to paediatric surgical care}

From the area of coverage $\left(\mathrm{km}^{2}\right)$ perspective, Sanaag has the largest area $\left(\mathrm{km}^{2}\right)$ for both surgical capable and bellwether hospitals. Maroodi-Jeex $\left(3624 \mathrm{~km}^{2}\right)$ has the smallest area of coverage for surgically capable hospitals (table 3). With a total of $118933 \mathrm{~km}^{2}$ of surface and covering $62.3 \%$ of the country, Sanaag's bellwether hospital was the closest facility to people from the entire region of Sool and some areas of Sahil and Togdheer. In contrast, Awdal $\left(9.350 \mathrm{~km}^{2}\right)$ had the smallest area of coverage for bellwether hospitals.

Analysis of the geographical access to surgical care revealed that when travelling by public transportation, $19 \%$ of the population is within a 2 hour distance from a surgically capable hospital, while $8 \%$ of the population is within a 2-hour distance from a bellwether hospital (figure 3A).
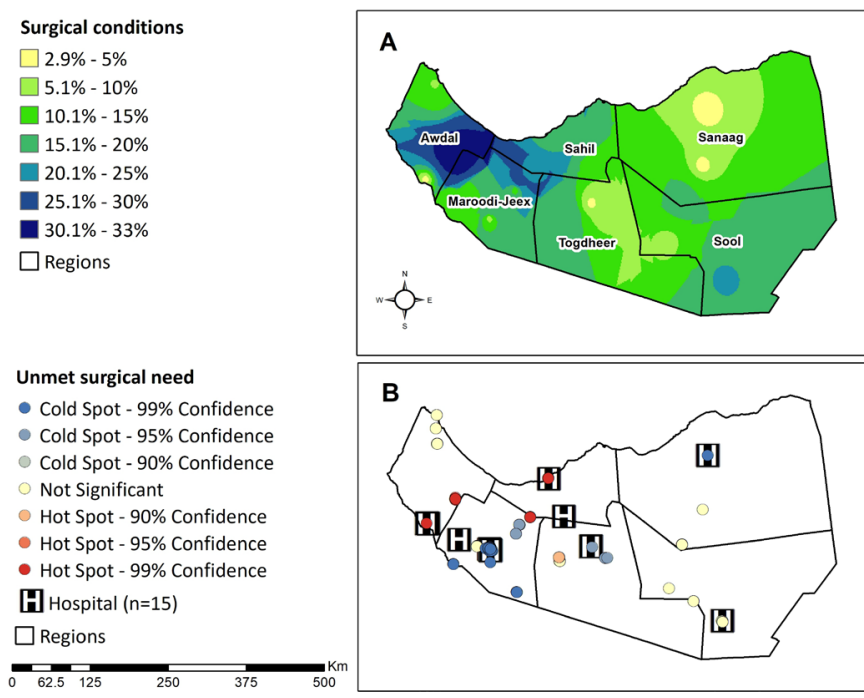

Figure 1 Geographical distribution of paediatric surgical conditions by region. (A) Predicted prevalence of total surgical conditions $(n=221)$ found among 196 children. (B) Hot spot analysis of untreated surgical conditions $(n=168)$ found among 196 children. Hot spots (red bullets) show clusters of data points with adjacent data points with high frequency of untreated surgical conditions. Cold spots (blue bullets) show clusters with adjacent data points with low frequency of untreated surgical conditions. 
A
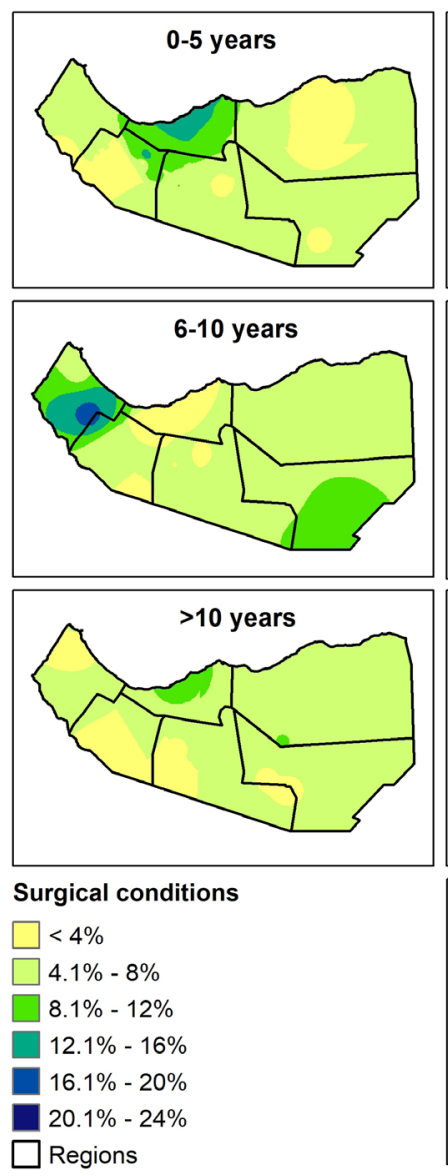

B
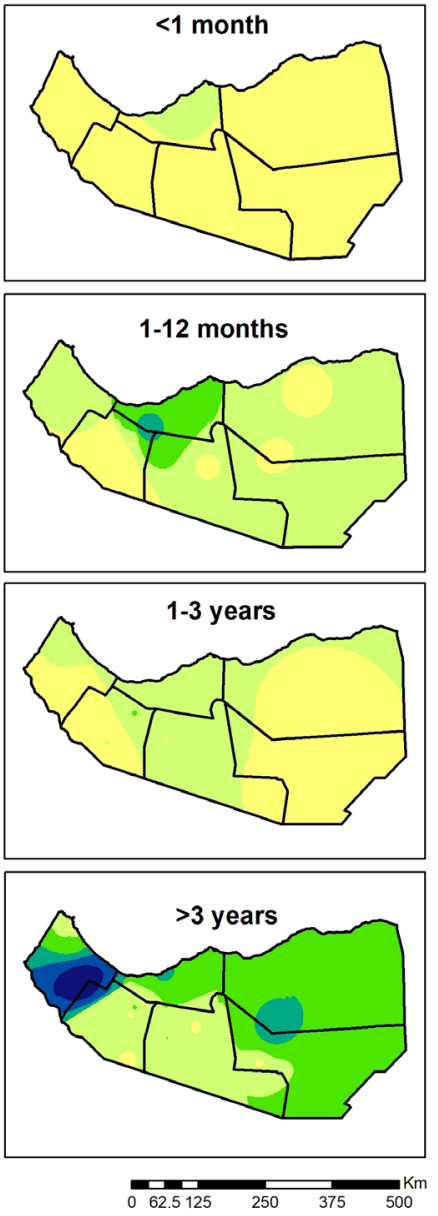

Figure 2 Geographical distribution of paediatric surgical conditions across Somaliland. (A) Total surgical conditions $(n=221)$ found among 196 children stratified by age. (B) Untreated surgical conditions $(n=168)$ found among 196 children stratified by time of delay to receive surgical care.

A
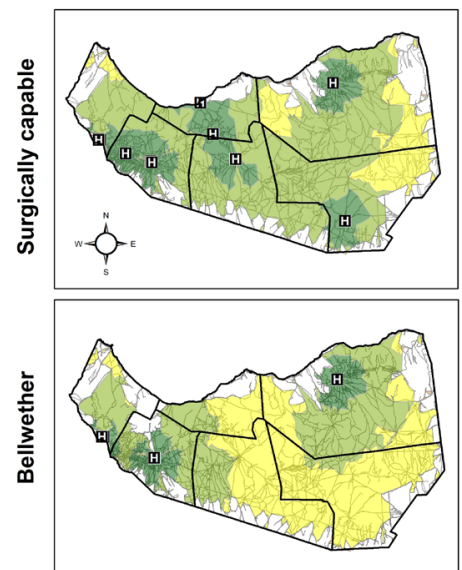

Service Area

2 hours or less $6-12$ hours $11-2$ days (20 hours
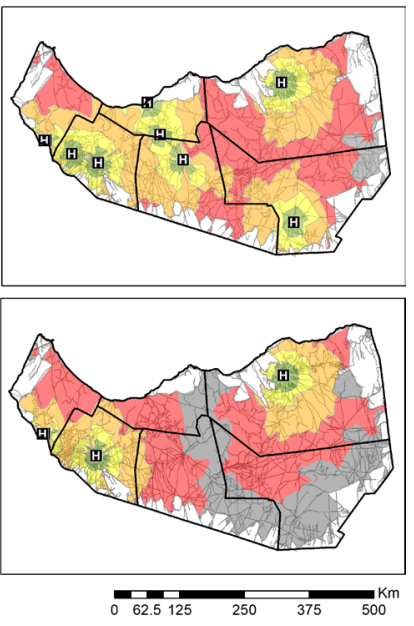

$\square$ Regions ㅂ Hospital - Road System

Figure 3 Service areas for paediatric surgical care within a 2-hour travel distance from surgically capable hospitals $(n=15)$ and bellwether hospitals $(n=5)$. (A) Service area calculated when travelling by public transportation $(30 \mathrm{~km} /$ hour). (B) Service area calculated when travelling by foot (5 $\mathrm{km} /$ hour). Note that the service area analysis is based on road systems. Then, the white areas across the four maps represent unreachable areas due to the absence of roads.

When travelling by foot, $0.6 \%$ of the population is within a 2-hour distance from a surgically capable hospital, while $0.2 \%$ is within a 2-hour distance from a bellwether hospital (figure 3B). None of the population in three regions, Sahil, Togdheer and Sool, were within a 2-hour distance from a bellwether hospital. When travelling by public transportation, travel time could reach up to 12 hours. However, when travelling by foot, travel time could be extended to more than 2 days.

Table 3 Regional description of catchment population covered within a 2-hour distance from surgically capable and bellwether hospitals, and crude area of coverage (calculated with Voronoi diagrams) for both types of hospitals

\begin{tabular}{|c|c|c|c|c|c|c|c|}
\hline & Total & Awdal & Maroodi J. & Sahil & Sanaag & Sool & Togdheer \\
\hline \multicolumn{8}{|l|}{ Service area } \\
\hline Child population (n) & 2022524 & 337305 & 822191 & 53978 & 272606 & 164041 & 361403 \\
\hline Surgically capable hospitals (n) & 15 & 3 & 6 & 2 & 1 & 1 & 2 \\
\hline $\begin{array}{l}\text { Catchment population (\%) } \\
\text { ( } 2 \text { hours by public transport) }\end{array}$ & 18.9 & 7.9 & 50.1 & 38.3 & 11.1 & 14.9 & 16.5 \\
\hline $\begin{array}{l}\text { Catchment population (\%) } \\
\text { ( } 2 \text { hours by foot) }\end{array}$ & 0.6 & 0.2 & 1.4 & 1.5 & 0.5 & 0.6 & 0.5 \\
\hline Bellwether hospitals (n) & 5 & 2 & 2 & 0 & 1 & 0 & 0 \\
\hline $\begin{array}{l}\text { Catchment population (\%) } \\
\text { ( } 2 \text { hours by public transport) }\end{array}$ & 7.5 & 6.5 & 32.3 & 0 & 11.1 & 0 & 0 \\
\hline $\begin{array}{l}\text { Catchment population (\%) } \\
\text { ( } 2 \text { hours by foot) }\end{array}$ & 0.2 & 0.2 & 0.6 & 0 & 0.5 & 0 & 0 \\
\hline \multicolumn{8}{|l|}{ Area of coverage $\left(\mathrm{km}^{2}\right)$} \\
\hline Surgically capable hosp. (mean) & 22737 & 5121 & 3624 & 9600 & 54926 & 46499 & 16455 \\
\hline Bellwether hosp. (mean) & 48569 & 9.350 & 26504 & $n / a$ & 118933 & $\mathrm{n} / \mathrm{a}$ & $n / a$ \\
\hline
\end{tabular}




\section{DISCUSSION}

The LCoGS proposed a target of at least $80 \%$ coverage of essential surgical care by $2030 .{ }^{3}$ Our study revealed that Somaliland is far behind this goal, with $0.2 \%-0.6 \%$ of its child population living within a 2-hour travel distance from bellwether hospitals and $8 \%-18 \%$ of its population within this travel distance from surgically capable hospitals. Surgical services are disproportionally distributed across the country, with one bellwether hospital covering $62 \%$ of the country. Disparities are greater among children travelling to the closest hospital by foot and in rural areas, where the delay in receiving surgery often exceeds 3 years.

Our study confirmed that geography is a barrier to surgical care for many children across Somaliland. However, reaching a health facility within 2 hours does not ensure a patient will receive treatment. Children in Somaliland experience additional barriers that prevent them from receiving surgery, including financial hardship, lack of time, lack of trust and cultural beliefs. ${ }^{33}$ In addition, there is a lack of surgical infrastructure and workforce across the country. Complex surgical care, including neonatal surgery, neurosurgical and cardiac procedures, involve a multidisciplinary team and highly specialised infrastructure, equipment and supplies. It also involves functioning administrative mechanisms to ensure the availability and maintenance of these resources. ${ }^{34}$

Given these complexities in the provision of surgical care for children, geospatial analysis can identify areas with geographical access to surgical care but with low rates of surgical delivery. For example, our analysis shows that southern Awdal has hot spots of untreated surgical conditions even when much of this area is within a 2-hour travel time from a surgically capable or bellwether hospital. Although children make up about $50 \%$ of the population, only $19 \%$ of inpatient beds are dedicated to children in Awdal. Additionally, Awdal lacks a surgical workforce and infrastructure, with only six surgeons, seven anaesthetists and no ventilators or anesthesiologists in the region. ${ }^{25}$ Another example is Maroodi Jeex, a region that concentrated most of the hospitals compared with other regions. However, rural areas of northern Madoori Jeex have low rates of surgical access due to the concentration of hospitals in the capital city of Hargeisa. Furthermore, workforce and infrastructure capacity are still inequitably distributed, with limited delivery of surgical care to children in most rural areas.

Geospatial tools, along with other analytic approaches, can help identify specific gaps in care, allowing for strategic allocation of resources to the areas of greatest need. For instance, in Sahil, where surgical conditions for children under-5 years old (ie, congenital anomalies) are common, specialised resources could be allocated to treat these conditions. ${ }^{24}$ Furthermore, preventive measures such as enhancing antenatal care and maternal nutrition might result in significant changes for this specific region. In contrast, in regions such as Awdal, allocation of resources and prevention programmes could focus on treating conditions specific to older children, such as injuries and traumas. ${ }^{24}$ Interventions to expand surgical services should also consider delays experienced by children, especially in rural areas, where children reported more than 3 years of delay. Delays in receiving surgery can result in lifelong disability or death. ${ }^{35}$ Thus, bringing surgical care closer to more rural communities through additional hospitals, improved referral systems for specialised surgical care, and increased educational efforts on identifying surgical needs could reduce delays to care and impact children's health in remote areas.

We found that the geographical access to surgical care remains low across Somaliland, particularly in the northwest and southeast areas of the country. After almost a decade of civil conflict, the country is left with damage and deterioration to road networks and healthcare infrastructure. ${ }^{21}$ In 2006 , only about $10 \%-15 \%$ of the primary roads in urban areas and networks connecting productive rural areas were considered in good condition, and many towns remained isolated from the urban capital of Maroodi Jeex due to the destruction of bridges. ${ }^{36}$ In addition, animal transportation of camels and donkeys continues to be a common means of transport in Somaliland. ${ }^{36}$ Not surprisingly, $100 \%$ of participants from Awdal, Sahil and Sanaag reported travelling to the closest health facility on foot. These practices suggest that fundamentally different interventions are required to scale-up surgical care for populations who access surgical care by foot compared with those that travel by public transportation.

Our analysis has several limitations. First, there is a lack of standardisation in the measurement of the first indicator of the LCoGS, the timely access to essential surgery. ${ }^{37}$ In particular, there is no consensus about how to categorise a bellwether hospital for children. ${ }^{37}$ We defined it as a hospital that performed the three bellwether procedures (laparotomy, open fracture fixation, and caesarean section) used for the analysis of surgical care for adults. However, this definition may not be transferable for analysis of surgical care for children, as children's surgical needs are different from adult's needs. Vissoci et al used a set of proxy procedures, including appendectomy, colostomy, hernia repair, laparotomy, and abdominal wall reconstruction, to assess the delivery of paediatric surgery in Brazil. ${ }^{18}$ However, further research is needed to establish a standardised indicator for children that can be used for comparisons on a global scale. Second, we applied interpolation analysis to a limited sample of geospatial data points across the country. We addressed missing data by applying extrapolation techniques for some of the most rural and less populated areas with limited geospatial data points. Third, the road system used for the service area analysis may limit accuracy of travel times, as topographic barriers and gaps between roads vary as a consequence of the past civil conflict. We attempted to overcome this limitation by using aerial base maps for comparison. Fourth, travel times are calculated with more accuracy if information on waiting times, traffic, stops, and speed is considered. However, in this study, we 
assumed a constant availability of transportation and a constant speed because of the lack of data on these categories. Therefore, our reported travel times may be an underestimation of the real travel times to access surgical care in Somaliland. Finally, we assumed all children inside the 2 hour threshold had equal accessibility to the healthcare facilities. However, previous studies demonstrated that lower utilisation rates are found for populations located further from the healthcare facilities. ${ }^{38}$ Although the distance-decay effect is often used to evaluate health systems in low-income and rural settings, ${ }^{39}$ this technique was not used in this study due to the lack of data.

\section{CONCLUSIONS}

In summary, our study demonstrated there is a need to scale up the surgical system to reduce disparities in the access to paediatric surgical care across Somaliland. We identified Sahil and Sool as the areas with the greatest need and the lowest coverage of essential surgical care. These are high-priority areas to allocate resources and health interventions that target the most vulnerable and forgotten populations. The economy of Somaliland has steadily improved over the last decade, consequently benefiting the health sector with an improved budget. ${ }^{23}$ This is an opportunity to strategically invest in the expansion of surgical services and promote development in road construction and transportation systems to reduce the geographical barriers to surgical care. A comprehensive framework is needed to address other delays in reaching care and receiving care, and thus truly ensure timely access to essential surgery. Interventions such as increasing the number and skills of community health workers are needed to address the delays in seeking care and receiving care.

\section{Author affiliations}

${ }^{1}$ Department of Public Health, Baylor University, Waco, Texas, USA

${ }^{2}$ Duke University Global Health Institute, Duke University, Durham, North Carolina, USA

${ }^{3}$ Edna Adan University Hospital, Hargeisa, Somalia

${ }^{4}$ Edna Adan Hospital, Hargeisa, Somalia

${ }^{5}$ Center for Spatial Research, Baylor University, Waco, Texas, USA

${ }^{6}$ Department of Surgery, Duke University Medical Center, Durham, North Carolina, USA

Acknowledgements We want to thank the Global Initiative for Children's Surgery (GICS) and the Center for Spatial Research at Baylor University for their support of this work. GICS (www.globalchildrenssurgery.org) is a network of children's surgical and anaesthesia providers from low-income, middle-income, and high-income countries collaborating for the purpose of improving the quality of surgical care for children globally.

Contributors SD, TC, MM and EAl oversaw all data collection efforts and contributed to the revising of the manuscript. KM conceptualised the study and contributed to the revising of the manuscript. CFC-C conceptualised the study, analysed the data, and contributed to the writing and revising of the manuscript. JC and JW contributed to the data analysis and revising of the manuscript. HER and ERS oversaw the project and contributed to the revising of the manuscript. GICS provided a critical revision of the manuscript. All authors read and approved the final version.

Funding The authors have not declared a specific grant for this research from any funding agency in the public, commercial or not-for-profit sectors.
Map disclaimer The inclusion of any map (including the depiction of any boundaries therein), or of any geographic or locational reference, does not imply the expression of any opinion whatsoever on the part of BMJ concerning the legal status of any country, territory, jurisdiction or area or of its authorities. Any such expression remains solely that of the relevant source and is not endorsed by BMJ. Maps are provided without any warranty of any kind, either express or implied.

Competing interests None declared.

Patient consent for publication Obtained.

Ethics approval Institutional review board (IRB) approval was granted from Duke University. Since Somaliland does not have a national IRB, a letter of approval was granted from the Somaliland Ministry of Health. Participants in the community survey offered verbal consent for study participation. A parent or guardian provided consent for children younger than 15 years old, and children between the ages of 12 and 15 provided additional assent.

Provenance and peer review Not commissioned; externally peer reviewed.

Data availability statement Data are available upon reasonable request. Data are available by request by emailing Emily_r_smith@baylor.edu.

Supplemental material This content has been supplied by the author(s). It has not been vetted by BMJ Publishing Group Limited (BMJ) and may not have been peer-reviewed. Any opinions or recommendations discussed are solely those of the author(s) and are not endorsed by BMJ. BMJ disclaims all liability and responsibility arising from any reliance placed on the content. Where the content includes any translated material, BMJ does not warrant the accuracy and reliability of the translations (including but not limited to local regulations, clinical guidelines, terminology, drug names and drug dosages), and is not responsible for any error and/or omissions arising from translation and adaptation or otherwise.

Open access This is an open access article distributed in accordance with the Creative Commons Attribution Non Commercial (CC BY-NC 4.0) license, which permits others to distribute, remix, adapt, build upon this work non-commercially, and license their derivative works on different terms, provided the original work is properly cited, appropriate credit is given, any changes made indicated, and the use is non-commercial. See: http://creativecommons.org/licenses/by-nc/4.0/.

\section{ORCID iDs}

Cesia F Cotache-Condor http://orcid.org/0000-0002-3401-9565

Emily R Smith http://orcid.org/0000-0002-1745-5728

\section{REFERENCES}

1 Gajewski J, Bijlmakers L, Brugha R. Global Surgery - Informing National Strategies for Scaling Up Surgery in Sub-Saharan Africa. Int $\checkmark$ Health Policy Manag 2018;7:481-4.

2 Debas HT. Progress in global surgery comment on "global surgery - informing national strategies for scaling up surgery in sub-saharan africa". Int J Health Policy Manag 2018;7:1056-7.

3 Meara JG, Leather AJM, Hagander L, et al. Global surgery 2030: evidence and solutions for achieving health, welfare, and economic development. The Lancet 2015;386:569-624.

4 Knowlton LM, Banguti P, Chackungal S, et al. A geospatial evaluation of timely access to surgical care in seven countries. Bull World Health Organ 2017;95:437-44.

5 Juran S, Broer PN, Klug SJ, et al. Geospatial mapping of access to timely essential surgery in sub-Saharan Africa. BMJ Global Health 2018;3:e000875.

6 Lilley R, de Graaf B, Kool B, et al. Geographical and population disparities in timely access to prehospital and advanced level emergency care in New Zealand: a cross-sectional study. BMJ Open 2019;9:e026026.

7 Esquivel MM, Uribe-Leitz T, Makasa E, et al. Mapping disparities in access to safe, timely, and essential surgical care in Zambia. JAMA Surg 2016;151:1064-9.

8 Raykar NP, Bowder AN, Liu C, et al. Geospatial mapping to estimate timely access to surgical care in nine low-income and middle-income countries. Lancet 2015;385 Suppl 2:S16.

9 Musa GJ, Chiang P-H, Sylk T, et al. Use of GIS mapping as a public health Tool--From cholera to cancer. Health Serv Insights 2013;6:HSI. S10471-6.

10 Auchincloss AH, Gebreab SY, Mair C, et al. A review of spatial methods in epidemiology, 2000-2010. Annu Rev Public Health 2012;33:107-22.

11 Leonardo LR, Crisostomo BA, Solon JAA, et al. Geographical information systems in health research and services delivery in the Philippines. Geospat Health 2007;1:147-55. 
12 Tansley G, Stewart BT, Gyedu A, et al. The correlation between poverty and access to essential surgical care in Ghana: a Geospatial analysis. World J Surg 2017;41:639-43.

13 Gupta S, Groen TA, Stewart BT, et al. The spatial distribution of injuries in need of surgical intervention in Nepal. Geospat Health 2016;11:359.

14 Lin N, Nwanna-Nzewunwa O, Carvalho M, et al. Geospatial analysis of trauma burden and surgical care capacity in Teso Sub-region of eastern Uganda. World J Surg 2019;43:2666-73.

15 Farber SH, Vissoci JRN, Tran TM, et al. Geospatial analysis of unmet surgical need in Uganda: an analysis of SOSAS survey data. World J Surg 2017;41:353-63.

16 Smith ER, Vissoci JRN, Rocha TAH, et al. Geospatial analysis of unmet pediatric surgical need in Uganda. J Pediatr Surg 2017;52:1691-8.

17 Tollefson TT, Shaye D, Durbin-Johnson B, et al. Cleft lip-cleft palate in Zimbabwe: estimating the distribution of the surgical burden of disease using geographic information systems. Laryngoscope 2015;125 Suppl 1:S1-14.

18 Vissoci JRN, Ong CT, Andrade Lde, Ld A, et al. Disparities in surgical care for children across Brazil: use of geospatial analysis. PLoS One 2019;14:e0220959.

19 Concepcion T, Mohamed M, Dahir S, et al. Prevalence of pediatric surgical conditions across Somaliland. JAMA Netw Open 2019;2:e186857.

20 Somaliland Central Statistics Department. Somaliland in figures 2018. Hargeisa, 2019

21 Leather A, Ismail EA, Ali R, et al. Working together to rebuild health care in post-conflict Somaliland. Lancet 2006;368:1119-25.

22 Devi S. Slowly and steadily, Somaliland builds its health system. Lancet 2015;385:2139-40.

23 Institute for Strategic Initiatives and Research. Somaliland budget brief 2020. Hargueisa, 201913

24 Butler EK, Tran TM, Nagarajan N, et al. Epidemiology of pediatric surgical needs in low-income countries. PLoS One 2017;12:e0170968.

25 Concepcion TL, Smith ER, Mohamed M, et al. Provision of surgical care for children across Somaliland: challenges and policy guidance. World J Surg 2019;43:2934-44.

26 Smith ER CT, Mubarak M, Shugri D. Poverty trajectories among families with children with surgical care in Somaliland. PLoS One. In Press 2019.

27 United Nations Population Fund. Population estimation survey 2014 for the 18 pre-war regions of Somalia, 2014.
28 Groen RS, Samai M, Stewart K-A, et al. Untreated surgical conditions in Sierra Leone: a cluster randomised, cross-sectional, countrywide survey. The Lancet 2012;380:1082-7.

29 Petroze RT, Calland JF, Niyonkuru F, et al. Estimating pediatric surgical need in developing countries: a household survey in Rwanda. J Pediatr Surg 2014;49:1092-8.

30 Butler EK, Tran TM, Fuller AT, et al. Quantifying the pediatric surgical need in Uganda: results of a nationwide cross-sectional, household survey. Pediatr Surg Int 2016;32:1075-85.

31 World Health Organization. Program in Glogla surgery and social change. WHO-PGSSC surgical assessment tool (SAT) Hospital Walkthrough. Available: https://www.lancetglobalsurgery.org/ implementation-tools [Accessed 21 Jul 2019].

32 Goodman LF, St-Louis E, Yousef Y, et al. The global initiative for children's surgery: optimal resources for improving care. Eur J Pediatr Surg 2018;28:051-9.

33 Concepcion TL, Dahir S, Mohamed M, et al. Barriers to surgical care among children in Somaliland: an application of the three delays framework. World J Surg 2020;44:1712-8.

34 Grabski D, Ameh E, Ozgediz D, et al. Global Initiative for Children's Surgery. Optimal Resources for Children's Surgical Care: Executive Summary. World Journal of Surgery 2019;43:978-80.

35 Kouame BD, N'guetta-Brou IA, Kouame GSY, et al. Epidemiology of congenital abnormalities in West Africa: results of a descriptive study in teaching hospitals in Abidjan: Cote d'Ivoire. Afr J Paediatr Surg 2015;12:51.

36 World Bank. Somali joint needs assessment. Infraestructure cluster report., 200690

37 Holmer H, Bekele A, Hagander L, et al. Evaluating the collection, comparability and findings of six global surgery indicators. $\mathrm{Br} J$ Surg 2019;106:e138-50.

38 McGrail MR, Humphreys JS. The index of rural access: an innovative integrated approach for measuring primary care access. BMC Health Serv Res 2009;9:124.

39 McGrail MR. Spatial accessibility of primary health care utilising the two step floating catchment area method: an assessment of recent improvements. Int J Health Geogr 2012;11:50.

40 Burrough PA, McDonnell RA. Creating continuous surfaces from point data. in: Burrough PA, Goodchild MF, McDonnell RA, et al., EDS. principles of geographic information systems. Oxford, UK: Oxford UniversityPress, 1998.

41 WFPGeoNode. Somalia road network (main roads), 2020. Available: https://geonode.wfp.org/layers/geonode:som_trs_roads_osm [Accessed 17 Aug 2018]. 